\title{
Challenges of failing to link monitoring and evaluation findings with development interventions in Limpopo province, South Africa
}

\begin{abstract}
The task of monitoring and Evaluation has been recently introduced to issues of governance in departments of the Republic of South Africa. The National government has also introduced a ministry of Planning, Monitoring and Evaluation. The introduction of this ministry follows the realisation of poor implementation of policies introduced mainly with the view to empower poor communities by improving their living conditions. The National government, as part of introducing Development Interventions developed the National Development Plan 2030 aimed at realising significant if not total development in the country in the year 2030. Provinces had to follow suit and introduce their development plans aligned to the national one. Limpopo Province responded by developing the Limpopo Development plan (LDP) for the years 2015/19 with the aim of getting part or complete development improvement by 2019 .

Through the use of qualitative methodology techniques it was found that all departments do not seem to be moving with required pace to realise goals of the LDP hence this study aiming at releasing findings that, if seriously considered by the Executive Council of the Provincial Government and be used as decision making tools will assist in speeding the delivery processes using Monitoring and Evaluation (M \& E) findings as decision making tool in all eleven departments of the Province. Although not all outcomes of the LDP 2015/2019 are probed examples taken from the 14 are used to depict the challenge of not linking $M \&$ E findings to development interventions as stated in the LDP 2015/2019. The way forward or intervention is then suggested in this study.
\end{abstract}

Keywords: national, development, plan, monitoring, evaluation, interventions, decision, making, linking, speeding, timeframes, citizens
Volume 2 Issue 6 - 2018

\author{
Bernard Naledzani Rasila \\ Department of Education, Limpopo Provincial Government, \\ South Africa
}

Correspondence: Bernard Naledzani Rasila, Department of Education, Limpopo Provincial Government, South Africa,Tel 08324I0772, Email Rasilabn@edu.limpopo.gov.za

Received: June 24, 20I8 | Published: December 26, 2018

\section{Introduction}

Governments across the world have Development Interventions. The Development Interventions are meant to uplift the living condition of citizens. These interventions also have timeframes. The Development Interventions are mostly reflected in the inauguration speeches leaders of Government present when they resume their office duties. The Development Interventions are categorised into two groups, the short and the long term plans. In South Africa for example, Development Interventions are based on the Medium Term Strategic Framework (MTSF). The current MTSF started in 2014 and will end in 2019 when the country goes for general election. The MTSF, in the context of Development Interventions is a government strategic plan for electoral term and reflects commitment made in the election manifesto of the ruling party, currently the African National Congress (ANC) in South Africa. These commitments remain empty promises if there is no mechanism to monitor and evaluate processes and impact during the MTSF. As argued by Wotela ${ }^{1}$ the discussions point out that $\mathrm{M} \& \mathrm{E}$ is a management and decision making tool but in most cases there is no link between Development Interventions and public policy. This renders the task of $M \&$ E ineffective as its findings remain just findings with no impact on decision making and service delivery plans.

In May 2010, South Africa's President Mr Jacob Zuma appointed a commission to focus on long term plans for Development Intervention with the aim of combating poverty and inequality as key objective. The commission then came out with the National Development Plan (NDP) 2030. Amongst others, the plan seeks to mobilise all South Africans and actively engage them on their own development, expansion of economy and building a capable and developmental state before the end of the year 2030. This however may not be realized without effective monitoring and evaluation exercise. Citing Wotela $^{2}$ indicates that the reason for absent or ineffective $\mathrm{M} \& \mathrm{E}$ of Development Interventions in some African countries was lack of political will. One reason for lack of political will is that most of findings of the task of M \& E may not be political desirable. On the other hand an organisation which is carrying out any activity needs to have some systems in place to ensure that its work is going according to the plan (Bakewell, Adams and Prat (2013). This process will also allow room for interventions.

In a desire to build effective M \& E, in 2009 the Government of South Africa created the ministry for Planning, Monitoring and Evaluation to strengthen service delivery. This saw departments and provinces embarking on building capacity in $\mathrm{M} \& \mathrm{E} .^{3}$ following the initiative by national government to come up with the NDP 2030, Limpopo Province also developed its own Development Intervention included in the Limpopo Development Plan (LDP) 2015/2019. These documents will become of value as the Development Interventions if plans, projects and their implementation are effectively monitored and evaluated. This study focuses on Development Intervention as 
set out in the LDP 2015/2019, the role or importance of M \& E in the realisation of goals set in the LDP 2015/2019 and some suggestion to follow. It will define Development, monitoring and evaluation, their purposes, unpack their components, processes and consider issues and debates from these key terms. The main Development Intervention in perspective will be the LDP 2015/2019.

\section{Literature Review}

\section{Development interventions in Limpopo province}

This section seeks to define and discuss Development Interventions in Limpopo Province. This will be more comprehensive if the two components, that of development and interventions are also simply defined. According to the LDP of 2015/2019, Development is defined as broad-based improvements in the standard and quality of living of people in a country, province or municipality including small villages. For development to happen there is a need of involvement of all stakeholders. These stakeholders include government, business, Non-Profit Making organisations (NPO) and citizens themselves. Citizen participation in matters of their development is emphasised more on local sphere of government in South Africa as per the White Paper on Local Government of $1998 .^{2,4}$ On the other hand, interventions are plans made or established to contribute in change from one advancement stage to the other. In Limpopo, government has developed the Limpopo Development Plan 2015/2019 as part of bringing intervention by developing strategies to improve living conditions of citizens of Limpopo.

The main focus of the plan is to bring development through intensification of Economic Transformation, social transformation and improvement of service delivery. Limpopo is one of the nine provinces in South Africa. Limpopo Province comprises five district municipalities namely Capricorn, Greater Sekhukhune, Mopani, Vhembe and Waterberg (LDP 2015/2019). All districts are dominated by rural areas to different degrees. This suggests there are many rural areas characterised by few economic opportunities. Limpopo Province shares international borders with districts and provinces of three countries of Botswana, Zimbabwe and Mozambique. As argued by Masiapato \& Wotela, ${ }^{2,4}$ rural areas in South Africa were exposed of poor service delivery processes by apartheid government, Limpopo rural areas were not immune from the discrimination development of the then apartheid regime of South Africa (SA) where only areas occupied by white people were provided more resources. This left the black dominated areas under-developed. The White Paper on Local Government (1999) seeks participatory democracy which leads to getting all citizens participate in their development initiatives. Unfortunately, even today, the Limpopo Province is hit by a large number of young, educated and skilled people migrating to other provinces for jobs and improved living conditions. They then leave economic activities' gap in their own province. Taking unemployment challenge standing to the $21.6 \%$ in Limpopo as per the quarterly labour force survey of 2017, indeed the province needs interventions which include improving on mining, agro-processing as reiterated in recent Provincial Economic Seminar.

The Limpopo Development Plan (LDP) (2015/2019) has target outcomes as part of Development Intervention. The 14 outcomes are as follows:

a) Outcome 1: Quality Basic Education

b) Outcome 2: Long and healthy life c) Outcome 3: Safety to all people

d) Outcome 4: Decent employment through inclusive growth

e) Outcome 5: Skilled and capable workforce

f) Outcome 6: Competitive economic infrastructure

g) Outcome 7: Comprehensive rural development

h) Outcome 8: Human settlement development

i) Outcome 9: Developmental local government

j) Outcome 10: Environmental protection

k) Outcome 11: Regional integration

1) Outcome 12: Developmental Public Service

m) Outcome 13: Inclusive social protection system

n) Outcome 14: Social cohesion

The LDP 2015-2019 is therefore the main Development Intervention guideline for the province of Limpopo in years 2015-2019. Through the Department of Cooperative Governance, Housing and Traditional Affairs (COGHTA) for example, the Province provides houses to qualifying citizens. This is one initiative that brings to previously disadvantaged people dignity in line with outcome 8 . Complains received from the beneficiaries include that there are houses that are left incomplete or are of poor quality. It can be implied that the main challenge is ineffective monitoring and evaluation function.

On the other hand, during 2005 grade 12 results announcement at the beginning of the 2016 year, MEC for Education, Mr Ishmael Kgetjepe announced names of schools referred to as "Serial poor performers" for performing poorly for five or more years in succession. Surely these schools will not be able to contribute in the realisation of the outcome 1 of the LDP 2015-2019, that of improving quality of basic education. The Limpopo Department of Education has developed Education Improvement Strategy which amongst others demands principals of the schools drafting the plans for their schools. This needs to be monitored by curriculum advisors, Circuit Managers and the Provincial office. However, as argued by Wotela ${ }^{1}$ it seems as if there is lack of political will as there are no consequences for the trend of poor planning which renders $\mathrm{M} \& \mathrm{E}$ findings ineffective as they do not contribute in decision making and improvement of service delivery. It is work as usual every year. The Department also seems to have no more plans beyond just developing the strategies as the strategy is used only for compliance and is not institutionalised so that it can be used for Development Intervention.

\section{The concept of monitoring and evaluation ( $m \& \mathrm{e})$}

Bakewell ${ }^{6}$ view Monitoring and Evaluation as a task that tracks continuous progress and periodically assess progress for the sake of accountability and improved management services. This is also echoed by Wotela ${ }^{1}$ who adds that the task of Monitoring and Evaluation provides for accountability, transparency and governance. Bakewell ${ }^{6}$ proceed to separate the task of monitoring and evaluation were they indicate that monitoring is done continuously checking mostly that the project is progressing as planned and enables adjustment in a methodical way. They further indicate that evaluation is mostly focusing on assessing periodically the relevance, efficiency and impact of the project or work in progress. In the context of development, it can be argued that it is only when monitoring and evaluation is effective that planned projects get completed and stay relevant and therefore be able to contribute on development intervention. As Wotela ${ }^{1}$ indicates, the task of Monitoring and Evaluation needs to be placed within development intervention and public policy. This can be possible if findings of monitoring and evaluation are used for decision making purposes in organisations including government structures. 


\section{Importance of $\mathbf{m} \&$ e to development interventions in Limpopo}

According to Statistics South Africa (Stats SA) 2011 Census, there are more than 5.4 Million people in Limpopo Province. However, the Limpopo Community Survey conducted by Statssa ${ }^{7}$ in 2016 indicates that the population has increased to 5.8 million. STATSSA continues to indicate that the Limpopo Province is the fifth largest province in the country. It comes after Gauteng, Kwazulu-Natal, Eastern Cape and Western Cape. In terms of access to basic services, the Province has highest proportion of "Owned and fully paid-off" homes in the country with $65.4 \%$. About $7.5 \%$ of households in the province own their main dwelling. There are also development challenges that need intervention. These include the increase of the growth of shortage or decrease in access to piped water which is at $80 \%$ in 2016 . Electricity access increased to $93 \%$ in 2016 from $39.2 \%$ in 2011 . Generally, the survey indicates that poverty headcount in Limpopo has increased from $10.1 \%$ in 2011 to $11.5 \%$ in 2016 .

There are other challenges to development that needs intervention including poor road infrastructure and general poor living conditions hence the need for effective monitoring and evaluation on programmes including the increment of capability and skills to be able to join economic activities. In the Provincial Economic Seminar under the theme "An Industrialisation Path towards Creating Sustainable Jobs and Reducing Poverty for Limpopo Province", the Province committed to embark on effective planning so that they can attract investors. ${ }^{5}$ The Premier of the Province, Mr Stan Mathabatha commits to improve in matters of rural development through promotion of activities on mining, infrastructure, ICT, Agri-process and Knowledge economy. Just like the many announcements made during political speeches such as the State of Province Address 2016, the summit may end up not yielding positive results due to lack of monitoring and evaluation. A question may be why Monitoring and Evaluation?

As put by Bakewell ${ }^{6}$ Monitoring and Evaluation provide for accountability. This is because those implementing the project do so on behalf of others and they have to account. Wotela ${ }^{1}$ supports on the accountability role of monitoring and evaluation but also added that this task to some extent provides transparency and good governance. However, the task of monitoring and evaluation should be linked with development intervention and public policy. ${ }^{1}$ On the other hand, Adejuwon $^{8}$ strongly emphasised that there is a need to strengthen debates about the role, scope and performance of the institutions and organisations with the public sector. This demands for effective monitoring and evaluation as argued by Wotela, ${ }^{1}$ Bakewell ${ }^{6}$ and other authors. Rasila ${ }^{9}$ have a view that it is only if the community members get involved in matters of development is public services. They argue that community members are to be involved in matters of governance so that they also assist by contribution on matters of accountability. Rasila $^{9}$ continued to develop a model of communication that will increase access to maters of governance by community members. Bakewell ${ }^{6}$ added that the task of monitoring and evaluation improves performance. Once a mistake is deduced during Monitoring and evaluation of a project, it provides room for interventions. On the other hand, monitoring and evaluation provides room for learning. Lessons are learnt during the process of monitoring and evaluation. These lessons can be used in the running of future projects. While doing monitoring and evaluation task different stakeholders exchange views and improve in the way they communicate to each other.

\section{Relevance of $m \&$ e process for development interventions in Limpopo}

This section of the paper focuses on identifying components of monitoring and evaluation and probes their importance in development interventions in Limpopo. These components are Monitoring and Evaluation. Went into separating the two components and define them separately. They define Monitoring as a systematic and continuous assessment where progress of a project is monitored. The task of monitoring mainly seeks to find out if the project or work is going per plan and provide early chance of adjustments if there are challenges. On the other hand, defines evaluation as a periodical assessment seeking to check on the relevance, performance, efficiency and the impact of the project or any piece of work. Evaluation happens at a specific stage of the project. The process of monitoring and evaluation follows the project cycle. As Bakewell, ${ }^{6}$ puts it, monitoring and evaluation function has levels. These levels include different levels starting from outputs, outcomes and impact.

These authors continue to indicate that outputs include the tangible products which are delivered on the completion of the project activity. It asks a question-What was done. This question need to be answer well by all departments in order to contribute in the realisation of target outcomes of the LDP 2015/2019 such as access to quality basic education. What for example is going into making sure the education development strategy to make it effective. The outcomes level represents the observable change towards realising objectives of the project and provide room for checking what has happened at a certain stage of the project. When for example going to writing final 2017 grade 12 examination the department need to be able to indicate steps moved towards moving serial poor performing school to the positive direction. On the other hand, the impact concerns long term changes coming with the project. It is about the interventions on the lives of the stakeholders. In summary, the output level looks at the effort used, the outcomes is more on the effect while the impact of a project focuses on the change the project brings. As emphasises, a project starts at identification of the challenge, then comes the planning, implementation, monitoring and evaluation and if need be, going back to planning. According to the Policy Framework for Governmentwide monitoring and Evaluation Systems (GWMES) ${ }^{10}$ if there is not monitoring and evaluation it is more likely that the project may install or take an opposite direction from conceptual objective. The following statement used in the GWMES summarizes what may happen should there be no monitoring in all stages of the project: "There was an important job to be done and everybody was sure somebody would do it. Anybody could have done it, but nobody did it. Somebody got angry about that, because it was everybody's job. Everybody thought anybody could do it, but nobody realized that everybody wouldn't do it. It ended up that everybody blamed somebody when nobody did what anybody could have done" GWMES. This indicates that each process of the project needs to be monitored and evaluated at all the time of implementation. The GWMES also indicates that the process of monitoring and evaluation involves collection of data, processing the data, analyses there-of and then compilation of a report. This is what Limpopo does with the aim of improving in development interventions. The office of the Premier has the Provincial Monitoring and Evaluation branch which oversees service delivery across the province. All other departments then develop their Monitoring and Evaluation systems including establishing directorates for the task. According to the Department of Education Policy on monitoring and evaluation ${ }^{11}$ it has been noted that there is a need to strengthen and 
stimulate the performance of government so that its programmes yield the desired outcomes.

Wotela ${ }^{1}$ argued that the task of monitoring and evaluation is a management and decision-making tool. However, there is a challenge that in Limpopo, this function is not linked to development interventions. This is because the function of monitoring and evaluation is not institutionalised but done haphazardly. The function of monitoring and evaluation should be aligned with the planning. This element does not exist in monitoring and evaluation in the province. It then leads to development interventions fail and projects not yielding desired results.

\section{Shortfall of $\mathbf{m} \&$ e processes in government}

It is more often that the target or indicator that is not well crafted end up coming with incomplete results. An example is when the target is just "Building the rehabilitation centre in Polokwane Town". Surely when the centre gets complete both the stakeholders and government will agree that the target has been achieved. This however does not provide complete picture. What matters most is not the centre that is complete alone, the complete research will explain long term achievement or benefit brought in by completion of the centre. An example in this regard will be "major changes brought in by the centre such as drop on drug use and for example more youth out of drugs and becoming responsible people who will build health society". This argument calls for Results Based Management (RBM). The RBM can be described as organisational governance paradigm that focuses on actual effect brought by the project. The project has to bring changes that occur beyond bureaucratic process and activities. Taking some of the outcomes as examples, success in Quality of Basic Education (Outcome 1) should not be measured only by the number of State-ofThe Art Schools built within the societies but long term results that will come out of the schools built such as producing better students fit for higher education and then becoming economic active persons as they will be well educated to access economic benefits. Success in building comprehensive rural development on the other hand should not be measured by number of houses built but dignity and long term results coming out of them (outcome 7). Long health life (Outcome 2) should also not be measured by number of hospitals built but long term results anchored by existence of the infrastructures.

Figure 1 show the cycle of M \& E with Inputs indicating what resources were brought in for the project such as funds, human resources and others. This stage is followed by the activities indicating implementation actions taken for the project. This will be followed by the outputs showing the results coming from the combination of resources and activities done to the stage at which evaluation is done. (e.g. the rehabilitation centre is complete). Then there is an outcomes stage which is on how the project benefits the target audience such as the fact that they now attend closer to their home. However, this cannot be the ultimate benefit for the entire society around the centre at a long term basis. The Impact of having the centre should be broadly scrutinised to be the long term goal anticipated for the benefit of all. In summary when evaluating a project the two questions are critical: What do we do to get project running (Inputs and Activities)? And What are achievements from the project (Outputs, Outcomes and Impact)? The last questions should be asked together with special concentration on the long term IMPACT.

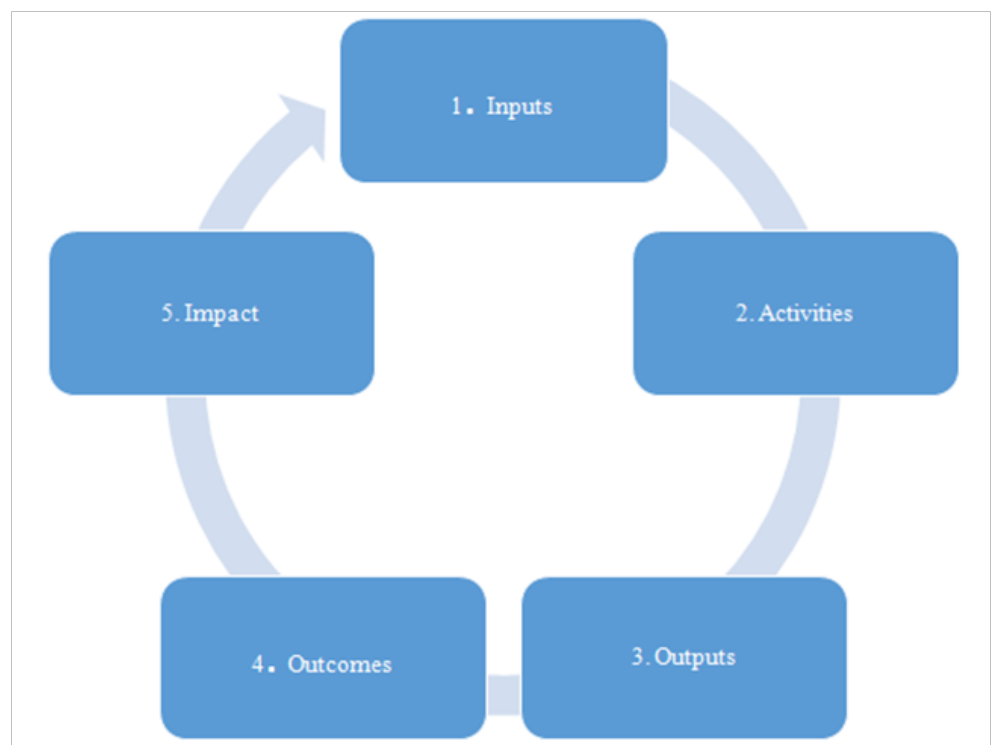

Figure I The following diagram shows important steps of Monitoring and Evaluation with focus on effective evaluation or Result Based Monitoring and Evaluation.

\section{Finding}

This section focuses on the findings based on the realisation as per study of the link between Monitoring and Evaluation function in Limpopo Province. Monitoring and Evaluation is meant for the people committed to social development and eager to speed up the process of development interventions. ${ }^{6}$ This is also supported by Adejuwon ${ }^{8}$ who argues that many governments in Africa saw decline in levels of service delivery. The decline in levels of service delivery comes with declining of development interventions. The $\mathrm{M} \& \mathrm{E}$ as indicated by Wotela ${ }^{1}$ is a decision making tool. It is unfortunate that in government such as that of the Limpopo Province function of monitoring and evaluation is not linked to planning. Departments in the Province also lack the desire to regard importance of monitoring and evaluation hence they do not link this task to their planning.

As the function of $M \& E$ provide accountability it is imperative that each institution develop effective monitoring and evaluation 
tools. Government may not experience projects collapse if planning, monitoring and evaluation is effectively done and this can be an anchor of development interventions. It is unfortunate that people are still complaining of half complete projects such as housing, roads and other community projects.

As per the Basic Concepts of Monitoring and Evaluation ${ }^{12}$ monitoring and evaluation should be used with the aim of organisational learning. This can assist in avoiding repetition of mistakes in different development interventions. Lessons learnt from one get used in improving on other interventions. Monitoring and evaluation can also be used to solicit support for programmes. However, there are similar projects that collapse in the same trend. The Mapungubwe festival of the Department of Sport and Culture in the province is the initiative aimed at contributing in economic boost in line with outcome 4 of the LDP 2015/19. However, attendance to the event does not show significant improvement in the past five years. This suggests that there is no effective $\mathrm{M} \& \mathrm{E}$ to be able to provide good lessens or monitoring and evaluation findings are not used as decision-making tool. It can be argued that government of South Africa, Limpopo included is known to have positive policies for Development Interventions. However, there is a need to improve in the implementation of the policies. This surely can be achieved through effective $\mathrm{M} \& \mathrm{E}$ function which will demand for accountability.

The Basic Concepts of Monitoring and Evaluation ${ }^{12}$ also indicates that government of South Africa should note that even its people are no longer interested in the creation of laws but outcomes of well planned projects. The importance of monitoring and evaluation is also emphasised as integral and distinct part of programme preparation and implementation. This is according to the UNICEF, Programme policy and procedure manual. ${ }^{11}$

The M \& E system puts step-by-step checking on intended goals of the projects or the intended impact. The intended impact has baring on the planning of the intended outcomes and objectives of the project. This will determine the inputs that may include all that will be used towards realisation of the goals. It gives direction on the activity plan which involves process or action to produce desired output The output then becomes relevant to the realisation of the intended objective. This lacks in many development interventions as outlined in the LDP 2015-2019 in Limpopo.

The Limpopo Development Plan (2015/2019) remains with two years as it is meant to bring development interventions as planned before the end of 2019. There are 14 outcomes to be achieved. These include provisioning of quality basic education, safety for all and creation of decent employment, to mention a few. These outcomes are set for different departments and other state own institutions operating in the Province. Some of these do not have monitoring and evaluation system nor capacity to create such. This implies that the level of monitoring and evaluation is questionable. According to the NDP 2030, there has to be active engagement of citizens in their development. This implies that citizens themselves need to play a role in monitoring and evaluation. As indicated by Rasila, ${ }^{13}$ citizens can be involved in planning of the development by getting chance of face-to-face with those planning in government through structures such as Imbizos of public Participation Programme where they can raise issues of concern on programmes meant for their development. Done systematically, Imbizos can be another tool for monitoring and evaluation and increase accountability. However, as argued by Rasila, ${ }^{13}$ level of committing community members by government institutions is limited. In general therefore, there is no institutionalised link between the function of monitoring and evaluation and development intervention.

\section{Conclusion}

According to the World Bank Report on M \& E (213), in order to maximize impact of $\mathrm{M} \& \mathrm{E}$ on development interventions, the $\mathrm{M} \&$ E function must be linked to impact evaluation. Impact Evaluation is a method used at the result-stage of project to analyse different outcomes. The report continues to indicate that M \& E can be used increase transparency and therefore raise awareness and promote debates on running of development interventions. The results of $\mathrm{M} \&$ E function therefore can be used as part of budget-decision making. According to the Handbook on Monitoring and Evaluation for Results $^{14}$ the M \& E activities are responsible for the intensified focus on outcomes by shifting toward better measurement of performance that will lead to more systematic reporting. Systematic reporting, it can be argued, fosters organisation culture of learning, transparency and accountability.

On the other hand, Kusek \& Ray ${ }^{15}$ introduced ten steps to a ResultBased $\mathrm{M} \& \mathrm{E}$ which are relevant for development interventions in Limpopo province. The first step in $\mathrm{M} \& \mathrm{E}$ function is to conduct readiness assessment to make sure all involved in the process are ready. There is again the need to check if conditions of the project will allow for $\mathrm{M} \& \mathrm{E}$ processes to avoid waste of resources. Those involved in M \& E activity should also agree on intended outcomes of the M \& E. Stakeholders need to understand what is expected during the process of M \& E. Performance indicators to be monitored need to be set out. As Kusek \& Ray (2004) continue, the other step is to establish process of gathering data on the indicators. To make sure results contribute to improved development intervention, the planning for improvement should be developed through selecting result target. The evaluation results are then used to support Result-Based Management System. Through finding reporting step, the gains, benefits and failure on the process of the project it is then revealed as part of feedback. The findings are then used for decision making to improve service delivery in Limpopo. ${ }^{16}$

In Limpopo and with the desire to link $\mathrm{M} \& \mathrm{E}$ function to Development Interventions as outlined LDP 2015/2019, it is recommended that that there is an evaluation and tracking plan for all 14 outcomes targeted for this MTSF. This plan then will be used to track progress quarterly on annually as it will involve field visits to where the outputs are put as mandates. With clear evaluation terms, it is more likely that come the end of the MTSF there will be tangible results. As indicated by Wotela ${ }^{1}$ problems or identified mess will be dealt with and conceptually the function of $\mathrm{M} \& \mathrm{E}$ will be linked to development interventions. All will then be characterised by evaluation that puts more importance on the long term impact of the project and not just numbers. Results should be based on demand for quality above quantity. This however does not suggest quantity findings are not important but that they have to be used to go forward to the long term impact. In conclusion, it can be argued that evaluation on Provincial Development Interventions is important to improve performance, accountability and generate knowledge on the running of interventions. It is only through evaluation that decision-making becomes relevant hence a need to link M \& E with development Interventions.

\section{Acknowledgments}

None. 


\section{Conflicts of interest}

The author declares that there are no conflicts of interest.

\section{References}

1. Wotela k. A proposed monitoring and evaluation curriculum based on model that institutionalises Monitoring and Evaluation. African Evaluation Journal. 2017;(5)1:8-25.

2. Wotrela K. Using systems thinking to conceptually link the monitoring and evaluation function within development interventions and public policy. The Journal for Transdisciplinary Research in South Africa. 2017:13(1):1817-4434

3. Monitoring and Evaluation for better development results. UK: The World Bank; 2013.

4. Masiapato N. Conceptual framework for subnational citizen-based participatory democracy and empowerment: Case of Vhembe District Municipality. African Journal of public affairs. 2017;(9)5:103-122.

5. Mabanga T. Infrastructure essential for limpopo's continued growth. Johannesburg: Mail \& Guardian; 2016. 8 p.

6. Paul Helepi. Basic concepts of monitoring and evaluation. Pretoria: Public Service Commision of South Africa; 2008. 28 p.

7. Stassa. Limpopo Community Survey. Pretoria: Statistics South Africa; 2016. $107 \mathrm{p}$.
8. Adejuwon D. Enhancing public accountability and performance in Nigeria: Periscoping the impediments and exploring imperitive measures. Africa's Public Service Delivery \& Performance Review. 2014:(2)1;82-92.

9. Rasila B. Citozen participation in local Government: The importance of effective communication in Rural development. International journal of community development. 2013;(1)1:12-18.

10. Policy Framework for government-Wide Monitoring and Evaluation Systems (GWMES). Pretoria: SAMEA; 2009. 28 p.

11. Programme policy procedures manual. New York: UNICEF; 2003. 327 $\mathrm{p}$

12. Zwane EM. Education LD. Policy on montoring and Evaluation Polokwane: Limpopo Department of Education; 2011.

13. Rasila BN. An effective communication framework for rura development. Prime journal of social science. 2014;(3)3:612-617.

14. Handbook on monitoring and evaluation for results. New York: United Nations; 2002. $282 \mathrm{p}$.

15. Kusek JZ. Ten steps to a Result-Based Monitoring and Evaluation. Washington DC: The World Bank; 2004. 366 p.

16. Statssa. Quarterly labour force survey. Pretoria: Statistics South Africa; 2017. $131 \mathrm{p}$. 